\title{
浙江舟山海岸带渗漏水沉淀铁泥中的微生物矿化作用
}

\author{
吴自军, 贾楠, 袁林喜, 孙立广* \\ 中国科学技术大学极地环境研究室, 合肥 230026 \\ *联系人, E-mail: slg@ustc.edu.cn
}

2007-07-20 收稿, 2007-11-26 接受

中国科学院知识创新工程重要方向项目(批准号: KZCX3-SW-151)和中国博士后基金(批准号: 20060400723)资助

摘要 运用现代微观研究手段(扫描电镜及透射电镜), 结合传统地质地球化学的研究方 法, 对浙江舟山古木埋藏环境下的海岸带渗漏水沉淀铁泥中的微生物矿化作用进行了研 究, 结果显示在铁泥中存在大量的嗜中性铁氧化菌, 其形貌特征与长杆形鞘状铁氧化菌 Leptothrix ochracea 和螺旋形鞘状铁氧化菌 Gallionella ferruginea 极为相似, 且这两种类 型的铁氧化菌丰度的分布明显受水体的物理化学组成的制约. 铁氧化菌细胞表面的有机 官能团、胞外聚合物和特殊的反应表面, 为渗漏地下水中成矿元素在细胞附近的富集沉

关键词

渗漏水

嗜中性铁氧化菌

微生物矿化

金属元素富集

古木层 淀提供了合适的成核位置和成核模板. 同时, 铁细菌在矿化过程中经历不同的阶段, 即 从细胞壁表面矿化、细胞内部部分矿化直至整个细胞完全被矿化. 铁氧化菌的矿化产物 主要为隐晶质的水铁矿, 由于该铁细菌的矿化产物包含铁氧化物和细菌有机质, 加剧了 金属元素尤其是 Fe, Co 的富集作用, 故对地下水环境中金属元素的迁移和归宿产生重要 影响.

铁是地壳中丰度居第四位的元素, 其在自然界 中以多种价态和矿物形式存在, 与铁循环有关的细 菌亦相应多种多样. 各种铁细菌最佳生长条件的专 属性很强, 即不同种属的铁细菌生长在不同的温度、 $\mathrm{pH}$ 及介质条件下 ${ }^{[1]}$. 一般将铁氧化细菌分为嗜酸 $(\mathrm{pH}<5)$ 和嗜中性 $(\mathrm{pH}>5)$ 两大类. $\mathrm{pH}<5$ 的酸性环境 中, 二价铁的化学氧化是非常缓慢的, 而嗜酸铁氧 化菌则能很快氧化二价铁, 这种现象在酸性矿坑水 及酸性热泉水中存在较为普遍, 参与该条件下主要 的菌种为氧化亚铁硫杆菌 (Acidithiobacillus ferrooxidans $)^{[2]}$. 国内外对嗜酸铁氧化菌的生长条件、 氧化动力学过程、微生物与矿物之间的相互关系及 作用机理等方面进行了较为充分的研究 ${ }^{[3 \sim 5]}$. 相比而 言, 嗜中性铁氧化菌在自然环境中的作用往往被忽 视. 这是由于人们一般认为, 在中性 $\mathrm{pH}$ 环境下, 二 价铁的微生物氧化作用很难与化学氧化过程相竞争, 故非生物因素在二价铁的氧化过程中占绝对主导作
用 ${ }^{[6]}$. 但近十几年来的研究表明, 铁氧化菌可明显加 速环境中二价铁的氧化, 这些过程在湖泊沉积物 ${ }^{[7]}$ 、

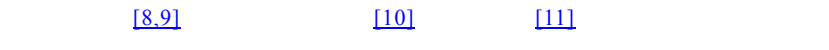
口 ${ }^{[12,13]}$ 等自然环境中相继被揭示. 如James和Ferris ${ }^{[9]}$ 通过对比模拟实验表明: 在中性 $\mathrm{pH}$ 的地下水环境中, 有铁氧化菌存在条件下的铁氧化速率是化学氧化速 率的 6 倍, 且微生物对铁氧化物形成的贡献达 $61 \%$, 其他类似研究亦显示在中性 $\mathrm{pH}$ 条件下 $50 \%$ 90\%的 铁氧化作用是由微生物参与下完成的, 且该过程易 于发生在好氧-厌氧界面 ${ }^{[12,14]}$; Weber等人 ${ }^{[15]}$ 详细阐 述了微生物在驱动铁的氧化还原过程中扮演重要的 角色, 并提供了在中性缺氧环境下铁氧化作用的分 子微生物学证据及其成矿机理. 微生物有助于矿物 的形成是由于微生物具有较大的比表面积和丰富的 表面电荷, 既具有从周围环境中吸附和富集金属的 能力, 又可以利用独特的细胞壁结构和胞外聚合物 作为矿物结晶的成核位置 ${ }^{[16]}$; 同时, 微生物细胞或 
有机组织可以作为矿物成核和结晶的模板，从而形 成具有规则晶体形貌和特征分布的矿物集合体 $[1,17,18]$.

研究不同条件下的现代环境中微生物所蕴含的 矿化信息, 对于更好地理解元素表生生物地球化学 过程 ${ }^{[19,20]}$, 认识铁氧化菌在矿化过程中所起的作用 以及探讨铁矿床的成因机制 [21]等方面具有十分重要 的意义, 同时也可为研究太古代叠层石及火星陨石 铁矿物中早期生命活动存在证据及生命演化特征提 供有益的借鉴 ${ }^{[22,23]}$. 以往虽有诸多研究指出古土壤 中铁细菌作用可形成磁铁矿并引起土壤剖面磁化率 的变化, 继而成为指示全球气候变化事件的标志性

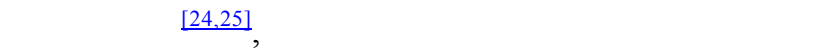
铁泥中微生物矿化作用及其对环境中元素迁移的影 响则鲜有报道. 本文运用微观研究手段(扫描电镜及透 射电镜), 结合传统的地质地球化学研究方法, 以浙 江舟山古木埋藏环境下海岸带渗漏水沉淀的铁泥为 研究对象, 初步探讨中性 $\mathrm{pH}$ 环境下铁氧化菌的生物 矿化机制及其对微量金属元素富集的影响.

\section{1 样品采集及实验方法}

\section{1 样品采集}

采样点位于浙江舟山朱家尖岛海岸带. 在该海岸 带中堆积有大量古木层(厚约 $3.3 \mathrm{~m}$ ), 经测算, 古木距 今年龄 $(4870 \pm 220) \mathrm{a}$, 有趣的是, 在距此约 $100 \mathrm{~km}$ 的大 忂岛海湾, 在完全相同的环境下也发现有完全一样的 古木层, 据此可推测古木的埋藏很可能与历史时期自 然环境灾害突变有关. 古木层的下表面为黑色的泥炭 层, 底部为花岗岩基岩, 在古木堆积的海岸带附近还分 布有多处洞穴以及正在成矿的褐铁矿层 ${ }^{[26]}$, 洞穴中有 缓慢的地下水下渗, 并且其底部沉淀大量的红褐色或 桔红色的铁泥. 选取 2 处渗漏地下水即TS-a和TS-b, 这 两处站位均位于潮上带以上未被海水淹没的海岸, 且 渗漏水下渗进入潮间带的褐铁矿层, 其中TS-a位于暴 露的古木层附近, TS-b相对TS-a大致处于同一海岸带水 平方向上, 两者相距约 $60 \mathrm{~m}$ (图 1). 现场利用美国 ORION多参数水质测定仪监测渗漏水的 $\mathrm{pH}, \mathrm{Eh}, \mathrm{DO}$ 等 参数. 同时采集水样, 经针头式过滤器(滤膜孔径 0.2 $\mu \mathrm{m})$ 过滤, 酸化后低温存放于聚四氟乙烯塑料瓶中, 回 实验室用于离子组成分析. 另外, 用消毒过的塑料勺分 别取约 $100 \mathrm{~mL}$ 的铁泥样品, 加入 $2 \%$ 的戊二醛低温保存 于密封袋中.

\section{2 分析方法}

(i) 水溶液和铁泥样品化学及矿物组成分析.

采用美国热电公司 Atomscan Advantage 的电感 耦合等离子体原子发射光谱仪(ICP-AES)和 Plasma Quad3 感应耦合等离子体质谱仪(ICP-MS)对水体和 铁泥样品中的常量元素和微量元素组成进行测定, 用仪器同步扣背景值法消除元素之间的相互干扰. 水体中二价铁用邻菲罗啉比色法测定, 测定波长为 $510 \mathrm{~nm}$. 在分析之前, 铁泥样品用超纯水清洗、离心 3 次, 以清除样品表面的杂质. 清洗好的样品于 $55^{\circ} \mathrm{C}$ 烘至近干, 再于 $105^{\circ} \mathrm{C}$ 完全烘干, 然后在玛瑙研钵中 磨成小于 200 目的粉末. 精确称取此粉末 $200 \mathrm{mg}$ 于 聚四氟乙烯小烧杯中, 依次加入 $1 \mathrm{~mL} H F, 1.5 \mathrm{~mL}$ $\mathrm{HCl}$ 和 $0.5 \mathrm{~mL} \mathrm{HNO}_{3}$, 在加热板上 $150^{\circ} \mathrm{C}$ 密封加热 24 $\mathrm{h}$, 随后加入 $0.25 \mathrm{~mL} \mathrm{HClO}_{4}$ 于 $120^{\circ} \mathrm{C}$ 将样品蒸至近干 不再冒白烟, 最后加入 $1 \mathrm{~mL} \mathrm{HNO}_{3}$ 和 $1 \mathrm{~mL}$ 水在加热 板上 $120^{\circ} \mathrm{C}$ 密封加热 $12 \mathrm{~h}$ 回溶样品. 所有测试过程均 使用标样进行质量监控, 所有待测元素分析误差均 小于 $5 \%$. 另外, 称取 $55^{\circ} \mathrm{C}$ 烘干后的铁泥样品约 $0.2 \mathrm{~g}$, 用 $\mathrm{X}$ 射线衍射仪(日本 D/MAX-rA)进行矿相分析. 工 作条件: 电压和电流, $40 \mathrm{kV}$ 和 $40 \mathrm{~mA}$; 扫描范围, $10^{\circ} \sim 70^{\circ}, 2 \theta$; 扫描步长, 0.02 ; 扫描速度, $0.5 \mathrm{~s}$ 步.

(ii) 扫描电镜 $(S E M)$ 显微观察. 取大约 $1 \mathrm{~mL}$ 用 $2 \%$ 戊二醛固定的铁泥样品放入塑料离心管中, 加 入 $10 \mathrm{~mL}$ 的超纯水混匀后离心 $5 \mathrm{~min}$ (离心速率: 5000 $\mathrm{r} / \mathrm{min}$ ), 去除上清液, 如此重复 3 次. 将清洗后的样品 移入 $250 \mathrm{~mL}$ 的烧杯中, 用玻璃棒搅动, 制成悬浮液, 再利用真空过滤器将样品固定在 $0.2 \mu \mathrm{m}$ 的微孔滤膜 上. 滤膜上的样品经过酒精 $(10 \%, 25 \%, 50 \%, 80 \%$, $100 \% \mathrm{v} / \mathrm{v})$ 梯度脱水后, 裁取小块滤膜固定在 Al 片上 并喷涂 $\mathrm{Au}$, 用荷兰 X'PERT PRO 型场发射扫描电镜 观察.

(iii) 透射电镜观察(TEM)和微区化学分析. $2 \%$ 戊二醛固定的铁泥样品用 $25 \%, 50 \%, 75 \%$ 和 $100 \%$ 的 系列乙醇梯度脱水各 $15 \mathrm{~min}$, 接着在 $50 \%(\mathrm{v} / \mathrm{v})$ 的环氧 树脂(TAAB)和乙醇中处理 $1 \mathrm{~h}$, 仅 TAAB 中浸泡 $1 \mathrm{~h}$, 然后于 $60^{\circ} \mathrm{C}$ 下聚合 $8 \sim 10 \mathrm{~h}$. 处理后的样品经超薄切 片 $(0.2 \mu \mathrm{m})$ 并用醋酸铀 - 柠檬酸铅双染, 用日本 JEOL-2010 型透射电镜(TEM)观察超薄切片样品中细 菌结构与矿物沉淀之间的关系, 并用其附带的 $X$ 射 线能谱仪(EDS)进行微区化学成分分析. 

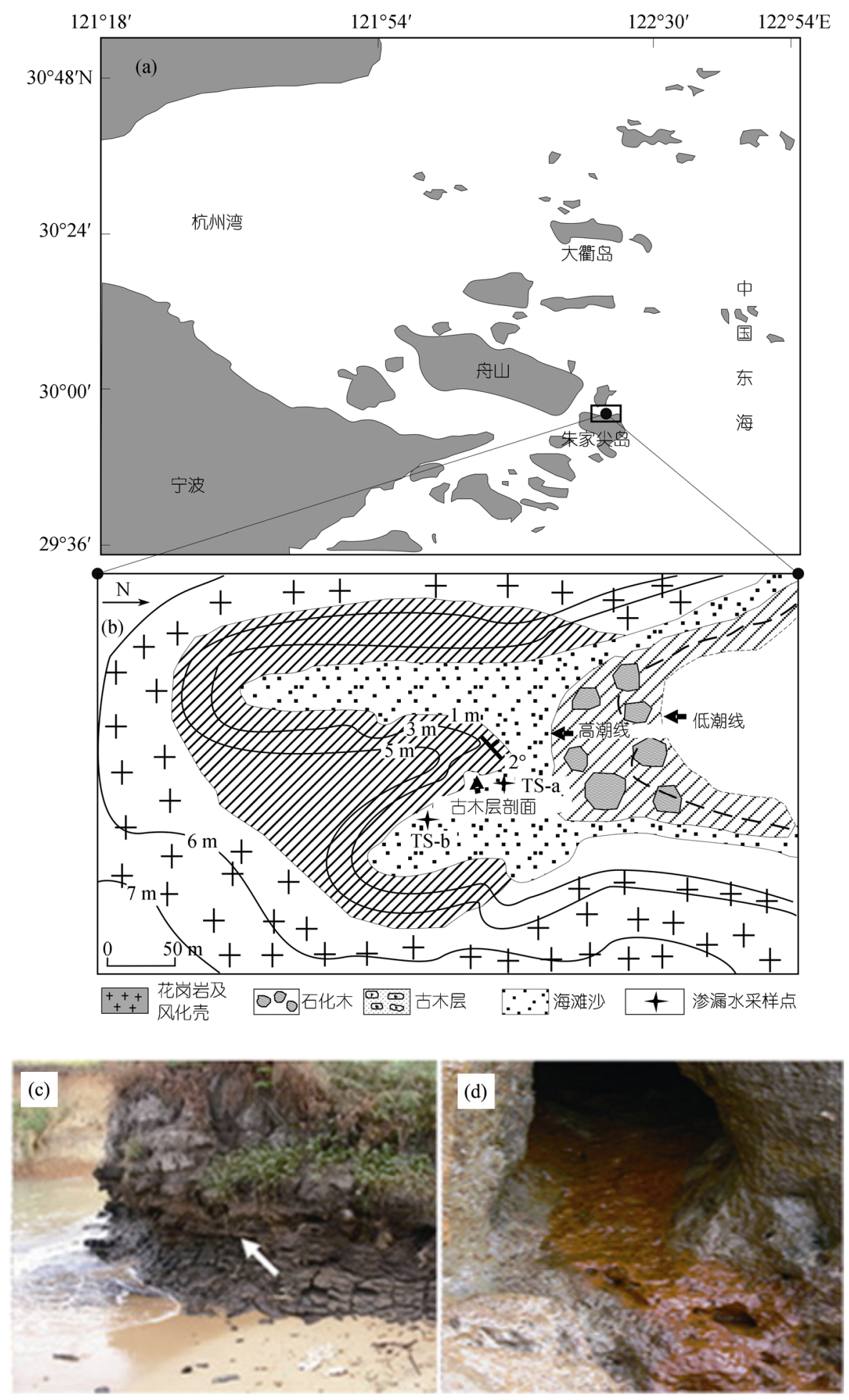

图 1 采样位置地质背景

(a) 采样点地理位置示意图; (b) 采样点地质剖面示意; (c) 堆积的古木层(箭头所示); (d) 桔红色渗漏地下水 
以上化学分析与电镜显微观察均在中国科学技 术大学理化实验中心完成.

\section{2 结果与讨论}

2.1 渗漏地下水的物理化学组成与嗜中性铁氧化菌 的分布

表 1 显示了 TS-a 和 TS-b 两处渗漏地下水的物理 化学组成. 从表 1 中可以看出, 两处地下水表现为近 中性 $\mathrm{pH}$ 、低氧、还原特征, 其阴离子组成主要为 $\mathrm{Cl}^{-}$ 和 $\mathrm{SO}_{4}^{2-}$, 阳离子组成主要为 $\mathrm{Ca}^{2+}, \mathrm{Mg}^{2+}, \mathrm{K}^{+}, \mathrm{Na}^{+}$和 $\mathrm{Fe}^{2+}$, 并且两处地下水的物理化学组成存在较大的差 异, 其中 TS-a 渗漏水呈中性偏酸, 溶解氧及阴阳离 子含量均较 TS-b 高.

表 1 采样点水体物理化学组成 ${ }^{\text {a) }}$

\begin{tabular}{|c|c|c|}
\hline 参数 & TS-a & TS-b \\
\hline$T /{ }^{\circ} \mathrm{C}$ & 23.4 & 25.0 \\
\hline $\mathrm{pH}$ & 6.00 & 6.99 \\
\hline $\mathrm{Eh} / \mathrm{mV}$ & 248.8 & 171.1 \\
\hline 溶解氧 $/ \mathrm{mg} \cdot \mathrm{L}^{-1}$ & 5.19 & 1.75 \\
\hline $\mathrm{Cl}^{-} / \mu \mathrm{mol} \cdot \mathrm{L}^{-1}$ & 740 & 689 \\
\hline $\mathrm{SO}_{4}{ }^{2-} / \mu \mathrm{mol} \cdot \mathrm{L}^{-1}$ & 1270 & 860 \\
\hline $\mathrm{NO}_{3}^{-} / \mu \mathrm{mol} \cdot \mathrm{L}^{-1}$ & 1.90 & 6.1 \\
\hline $\mathrm{Na}^{+} / \mu \mathrm{mol} \cdot \mathrm{L}^{-1}$ & 523.5 & 79.5 \\
\hline $\mathrm{K}^{+} / \mu \mathrm{mol} \cdot \mathrm{L}^{-1}$ & 202 & 111 \\
\hline $\mathrm{Mg}^{2+} / \mu \mathrm{mol} \cdot \mathrm{L}^{-1}$ & 533.6 & 99.3 \\
\hline $\mathrm{Ca}^{2+} / \mu \mathrm{mol} \cdot \mathrm{L}^{-1}$ & 720.3 & 86.2 \\
\hline $\mathrm{Mn}^{2+} / \mu \mathrm{mol} \cdot \mathrm{L}^{-1}$ & 25.54 & nd \\
\hline $\mathrm{Al}^{3+} / \mu \mathrm{mol} \cdot \mathrm{L}^{-1}$ & 20.08 & 1.08 \\
\hline $\mathrm{Si}-\mathrm{SiO}_{3}^{2-} / \mu \mathrm{mol} \cdot \mathrm{L}^{-1}$ & 94.95 & 34.26 \\
\hline $\mathrm{Fe}^{2+} / \mu \mathrm{mol} \cdot \mathrm{L}^{-1}$ & 198.8 & 23.8 \\
\hline 总 $\mathrm{Fe} / \mu \mathrm{mol} \cdot \mathrm{L}^{-1}$ & 241.6 & 26.5 \\
\hline
\end{tabular}

a) nd 表示浓度低于检测限

在该环境下, 水体的物理化学组成受古木、海水 及地下水共同作用的影响, 其主要表现在以下几个 方面: (1) 海岸带古木的长期堆积, 其腐烂过程产生 的有机酸加速周围基岩中铁等元素的滤出和迁移; (2) 受潮汐等动力作用影响, 部分海水与地下水发生 扩散混合, 导致 $\mathrm{Cl}^{-}, \mathrm{SO}_{4}{ }^{2-}, \mathrm{K}^{+}, \mathrm{Ca}^{2+}$ 和 $\mathrm{Mg}^{2+}$ 等离子含 量较高; (3) 洞穴附近丰富的有机质消耗环境介质中 大量氧，同时又缺乏与大气中氧的交换，致使水体呈 低氧还原态. 可能是由于 TS-a 和 TS-b 站位离埋藏古 木的间距及海水与地下水的混合程度的不同, 引起 两处渗漏地下水物理化学组成特征的明显差异.

渗漏地下水系统中, 不同来源水体的混合作用 引起氧化还原电位、氧含量和二价铁浓度发生明显的
梯度变化, 这为微生物活动提供了理想的生存环境 [9,27]. SEM观察结果表明: 铁泥样品中存在大量的杆 状和螺旋状的微生物, 与前人报道的结果相比照, 这 种微生物与长杆形鞘状铁氧化菌 Leptothrix ochracea (简称“L”) 和螺旋形鞘状铁氧化菌Gallionella ferruginea(简称“ “G”)极为相似(图 2(a), (b)), 这两种微 生物即为嗜中性铁氧化菌, 其长度一般在 5 20 $\mu \mathrm{m}$ 之 间. 从图 2 还可以看出, $\mathrm{L}$ 型铁氧化菌长杆形鞘的内部 为空心结构(图 2(a), (c)), 而 $\mathrm{G}$ 型铁氧化菌螺旋形鞘则 有多个似纤维条带丝组成(图 2(d)). 铁氧化菌外围长 杆状或螺旋状外鞘的化学成分主要为多糖, 外鞘对 铁细菌的生存起到很好的保护作用, 其一方面可避 免铁氧化菌被外围的矿物或细菌代谢产物所覆盖 ${ }^{[28]}$; 另外一方面起到御氧的作用, 阻止氧向菌体内部渗 透,使氧含量保持在一个低水平以防止氧中毒 $[29,30]$.

值得注意的是: SEM镜下观察发现两处渗漏地下 水沉淀铁泥中铁氧化菌的丰度明显不同, TS-a铁泥样 品中主要以螺旋状 $\mathrm{G}$ 型铁细菌的为主, 而 $\mathrm{TS}-\mathrm{b}$ 铁泥样 品中则以长杆状的 $\mathrm{L}$ 型铁细菌为主. 已有研究报道环 境中的有机酸、 $\mathrm{Cl}^{-}, \mathrm{SO}_{4}{ }^{2-}, \mathrm{Fe}^{2+}$ 等离子浓度大小会影 响二价铁的微生物氧化过程 ${ }^{[31]}$. 如James和Ferris ${ }^{[9]}$ 通 过测定加拿大Ogilvie地下水不同流距的水体中物化 参数和铁氧化菌的丰度, 发现不同类型的铁氧化菌 $\left(\mathrm{G}\right.$ 和 $\mathrm{L}$ 型)的丰度大小与 $\mathrm{Eh}, \mathrm{Fe}^{2+}$ 和 $\mathrm{O}_{2}$ 等参数之间存在 明显的响应关系. 尽管目前尚无法确切解释铁氧化 菌分布差异与水体物化组成之间相互关系的真正原 因, 但一般认为, $G$ 型铁氧化菌可能更适宜于相对较 高的氧和高矿化度的环境下生存, 利用 $\mathrm{O}_{2}$ 和 $\mathrm{CO}_{2}$ 作 为电子受体, 完成兼养或有机营养代谢过程 ${ }^{[32,33]}$; 而 $\mathrm{L}$ 型铁氧化菌生长条件对氧的要求相对较为严格, 一 般处于低氧水平,在代谢过程中通常以 $\mathrm{Fe}^{2+}$ 为唯一的 电子给体, 这亦是该种铁氧化菌分离纯培养十分困 难的主要原因 ${ }^{[12,34]}$. 通过对比分析两处地下水物理 化学组成并结合以上研究, 我们认为该渗漏地下水 铁氧化菌丰度分布差异可能主要受环境中 $\mathrm{O}_{2}$ 含量及 矿化度大小的控制, 而二价铁离子并不是主要的制 约因子, 这很可能是由于水体中二价铁离子浓度超 过了细菌代谢生长所需的最低限值.

\section{2 铁氧化菌与矿物的相互关系及其矿化过程}

图 2 显示了 $\mathrm{L}$ 型铁氧化菌长杆状和 $\mathrm{G}$ 型铁氧化 菌螺旋状的护鞘表面附着大量的矿物颗粒, 这些颗 

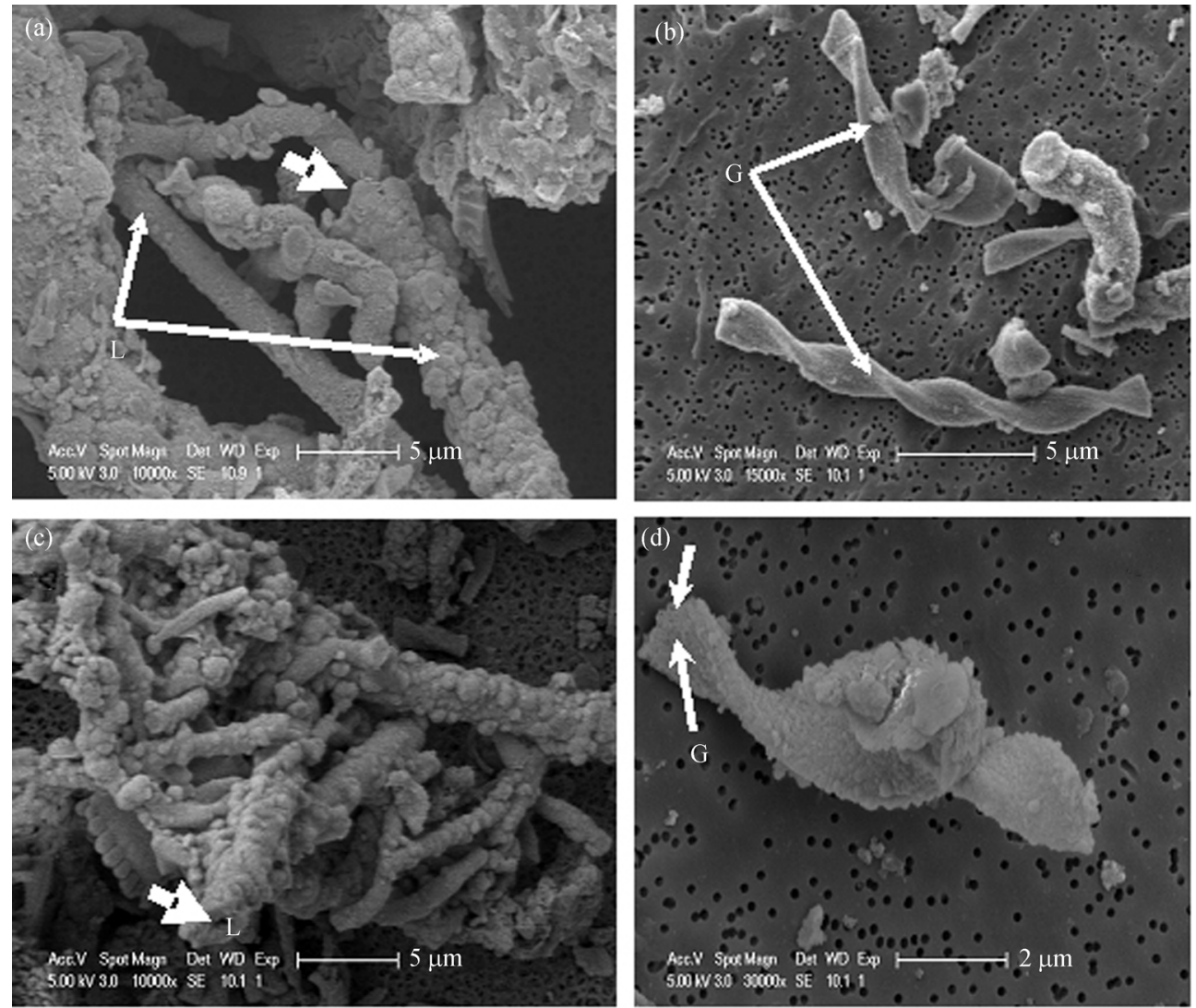

图 2 铁泥样品 SEM 图

$\mathrm{G}$ 表示 Gallionella ferruginea 铁氧化菌; L 表示 Leptothrix ochracea 铁氧化菌, 粗箭头指示 TS-b 样品中 L 型铁氧化菌长杆状鞘内部为空 心结构(a), (c)以及细箭头指示 TS-a 样品中 G 型铁氧化菌螺旋状鞘由多个似纤维条带丝组成(d)
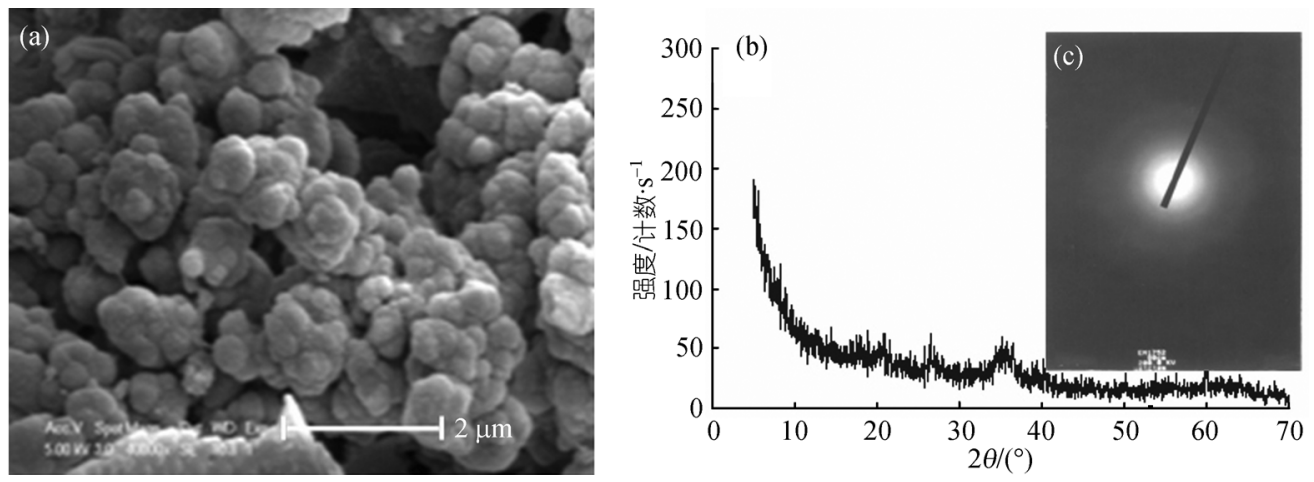

图 3 铁泥样品生物成因铁氧化物形貌扫描电镜(SEM)图(a)及其矿相分析((b)和(c))

粒一般呈不规则的球形，其大小为 $20 \sim 500 \mathrm{~nm}$ 之间 (图 3(a)). 一般认为, 与微生物作用有关的含铁矿物 主要有赤铁矿、针铁矿、磁铁矿以及隐晶质的矿物相 [31]. 本研究利用X射线衍射(XRD)图谱分析铁泥的矿 相组成, 结果显示其主要为一些晶形较差的隐晶质 铁矿物(图 3(b)). 另外, 矿物微区电子衍射花样为 2
环模式, 其 $d$ 空间距离分别为 2.5 和 $1.5 \AA($ 图 3(c)), 进 一步确定该矿物为水铁矿 (ferrihydrite).

TEM 观察进一步显示, 隐晶质水铁矿通常沉淀 在细胞壁外或者其胞外聚合物附近(图 4(a), (b)). 另 外, TEM-EDS 分析图谱显示细菌矿化产物的主要成 分为 $\mathrm{Fe}$, 结合采样点的地球化学组成以及电镜显微 

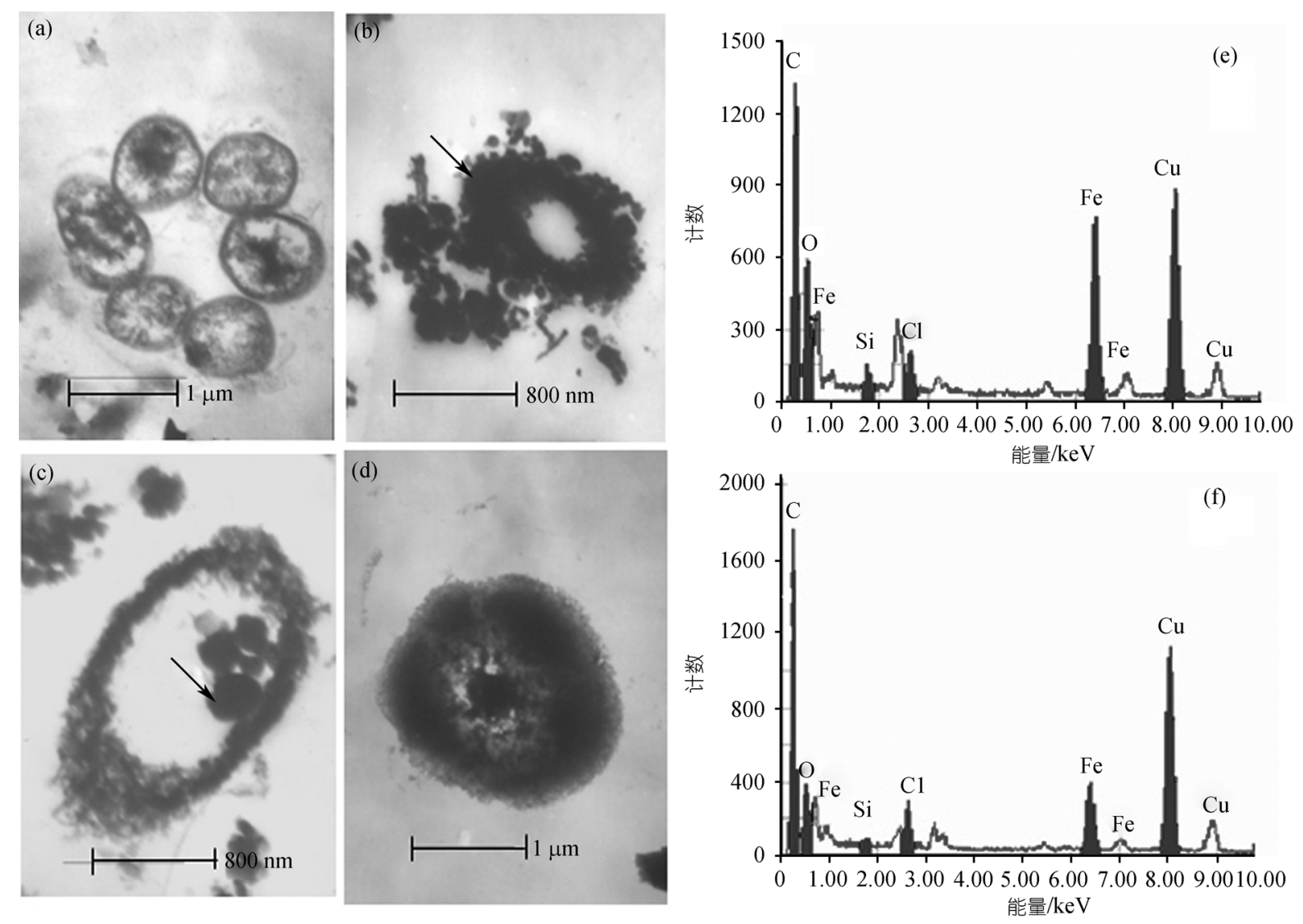

图 4 铁泥生物超薄切片样品中铁氧化菌 TEM 图像及 EDS 分析图谱

黑粗箭头表示 EDS 位置, (e)为(b)处的 EDS 图谱, (f)为(c)处的 EDS 图谱, 图谱中 $\mathrm{Cu}$ 峰来自铜网格

形貌观察, 表明参与该矿化过程的微生物确为嗜中 性铁氧化菌. 诸多研究认为, 铁氧化物形成过程中, 铁氧化菌所起的作用主要表现在以下 3 个方面: ( i ) 铁氧化菌细胞壁表面或者其胞外聚合物含有丰富的 两性功能团如- $\mathrm{COOH},-\mathrm{OH}$ 和- $\mathrm{NH}_{2}$ 以及多糖, 使得细 菌表面具有较强的反应活性并可充当化学反应的固 体颗粒, 一旦络合作用发生, 则化学键连的金属离子 能作为进一步络合和矿化作用的成核点 ${ }^{[16,35]}$; (ii ) 铁 细菌代谢活动可以催化、控制和影响局部的物理化学 过程(如 $\mathrm{pH}$, 亚铁, $\mathrm{CO}_{2}$ 含量等), 并能够降低体系中 矿物沉淀所需的过饱和度, 从而驱动化学反应和促 进矿物的沉淀 ${ }^{[36]}$; (iii) 铁氧化菌具有较大的比表面 积和丰富的表面电荷, 有利于吸附相关离子并结晶 沉淀, 与死细胞相比, 活细胞可以黏结和吸附更多的 金属离子 [27,37]. 这表明铁氧化菌细胞表面有机官能 团、胞外聚合物和特殊的反应表面, 为渗漏地下水中 成矿元素在细胞附近的富集提供了合适的电荷点、吸 附点和成核点, 并经历表面络合-成核-沉淀等一系列
反应, 最终形成生物成因铁矿物 ${ }^{[38]}$. 具体来讲, $G$ 型 或 $\mathrm{L}$ 型铁氧化菌在中性 $\mathrm{pH}$ 环境下, 利用 $\mathrm{Fe}^{2+}$ 为电子给 体, 加速环境中 $\mathrm{Fe}^{2+}$ 的氧化, 随着体系中 $\mathrm{Fe}^{2+}$ 不断被 氧化, $\mathrm{Fe}^{3+}$ 离子浓度显著上升和 $\mathrm{H}^{+}$浓度的降低, 势必 加剧 $\mathrm{Fe}^{3+}$ 的水解进程 $\left(\mathrm{Fe}^{3+}+n \mathrm{H}_{2} \mathrm{O} \rightarrow \mathrm{Fe}(\mathrm{OH})_{n}{ }^{(3-n)+}+n \mathrm{H}^{+}\right)$, 一旦体系中 $\left[\mathrm{Fe}^{3+}\right] /\left[\mathrm{H}^{+}\right]$达到固相平衡常数或临界饱和 点, 沉淀过程开始进行 ${ }^{[39]}$. 同时, 由于细菌表面与矿 物之间的相互作用, 其结果会导致体系的临界饱和 点进一步的降低, 这样铁更易于在溶液中发生不均 匀沉淀 $[27,40]$. 反过来, 铁氧化菌生物矿化作用亦是微 生物维系生命代谢的一种适应机制, 细菌通过分泌 多糖纤维等代谢产物将铁氧化物紧密固定在细胞的 表面, 促进铁氧化物在细胞表面不均匀成核; 与此同 时, 细菌在加速二价铁的氧化过程中, 引起细胞膜内 外界面的 $\mathrm{pH}$ 梯度明显增加, 其结果导致质子的运动 速率及细胞产能潜力的增大 ${ }^{[17,41]}$.

铁氧化菌的矿化可能经历不同的过程.在不同的 矿化阶段, 微生物的矿化特征有着明显的差异. 早期 
表面矿化阶段主要依靠鞘避免细胞壁和细胞质被矿 化(图 4(a), (b)), 在这一阶段中, 矿化过程的发生主要 是以活体铁氧化菌个体的表面为特征, 微生物的矿 化过程和细菌的生命过程是同时存在的, 渗漏地下 水水体中的成矿离子或因过饱和微环境的存在而沉 淀在微生物表面, 或因活体微生物胞外聚合物的键 合而聚集在微生物的表面.表面矿化阶段进行到一定 程度, 铁氧化菌开始衰亡, 其细胞壁和细胞质也开始 矿化(图 4(c)). 在许多矿化的样品中, 细胞内部已被 降解, 或已质壁分离, 但仍然可观察到胞外聚合物的 存在, 表现出了胞外聚合物较强的抗降解性. 一些研 究亦认为死细胞和有机质在吸附成矿阳离子方面甚 至比活细胞更有效, 伴随着有机质的降解, 菌席中凝 胶状矿物先驱物逐渐形成并进一步富集成矿元素, 直至整个细胞被矿化 ${ }^{[27,42]}$ (图 4(d)).

图 5 较清楚显示了 $\mathrm{G}$ 型铁氧化菌的矿化过程.铁 氧化菌在早期形成光滑的螺旋状护鞘(图 5(a)), 随着 鞘内外的 $\mathrm{Fe}^{2+}$ 的浓度梯度的增大, 鞘外开始沉淀一些 矿物颗粒(图 5(b)), 直到后期细菌外鞘被全部包裹(图 5(c)). Hallberg和Ferris ${ }^{[29]}$ 的研究亦认为 $G$ 型铁氧化菌 的矿化作用首先从螺旋状的护鞘内部开始, 且早期 的形成的有机构架为下一步矿物沉淀提供成核模板, 继而有利于矿物在细胞表面形成与富集. 完全被矿 化的细胞相对微生物有机组成更具惰性, 同时由于 其紧密键合了金属离子, 进一步限制了细胞的水解, 使得这些被完全矿化的细胞较易永久保存起来，成 为指示古代矿石或化石生物成因的重要证据 [21,31]. 因此, 理解和揭示铁氧化菌的微化石形态对于我们 认识火星乃至其他星球上的生命存在证据具有重要 的借鉴意义.
微生物不仅对矿物的核化和沉淀过程有重要的 影响作用, 同时还会控制矿物生长和相变. 铁氧化物 要经历不同的相变过程, 其首先沉淀形成过渡相矿 物, 最后相变为不含结晶水而可能含羟基的成熟矿 物 [31]. 不同的环境条件下, 嗜中性铁氧化菌作用的 铁氧化物的矿相不尽相同, 这种矿相差异则主要受 微生物、化学及其物理方面多因素共同制约: ( i ) 根 据Banfield等人 ${ }^{[43]}$ 提出的铁氧化物相变过程的晶体 生长模型, 布朗运动可引起沉淀小颗粒物的旋转和 聚集, 使其在三维结构中达到最低自由能, 从而促进 晶体生长及脱去聚合小颗粒表面的水分子, 形成 $\mathrm{Fe}-\mathrm{O}$ 键. 如前所叙, 细胞壁表面或者其胞外聚合物含 有丰富的有机功能团(如羟基, 磷羟基等), 使得亚铁 及成核水铁矿紧密键合在细菌的表面,束缚了小颗粒 的旋转，因此限制了小颗粒的聚合及晶体的生长. (ii) 从EDS图谱(图 4(e), (f))的分析可知, 铁氧化菌的矿化 产物主要组成为铁, 并含有少量的 $\mathrm{Si}(3 \% \sim 5 \%)$, 可能 由于硅含量太低的限制, 没有形成含硅的生物矿化 产物(如绿脱石), 这在XRD分析图谱中得到证实. 少 量 $\mathrm{Si}$ 的存在可能是由于与铁矿物发生共沉淀反应或 者水铁矿的吸附作用引起的, 而 Si则可影响铁氧化物 的晶体生长并阻止其向晶形良好的方向转化 ${ }^{[13,44]}$, (iii) 物理因素如温度的升高可明显加速布朗运动, 有利于水铁矿向有序的晶形发展. 与该渗漏水环境 下隐晶质的矿化产物相比, 海底火山或热液喷口等 高温环境下的铁氧化菌矿化产物主要为晶形良好的 针铁矿 $\stackrel{[12,45]}{ }$.

\section{3 生物成因铁氧化物对金属元素的富集}

分配系数 $\left(K_{d}\right)$ 是衡量金属元素在固相中富集程 度的一个重要参数. 其计算方法可根据经验公式 ${ }^{[39]}$ :
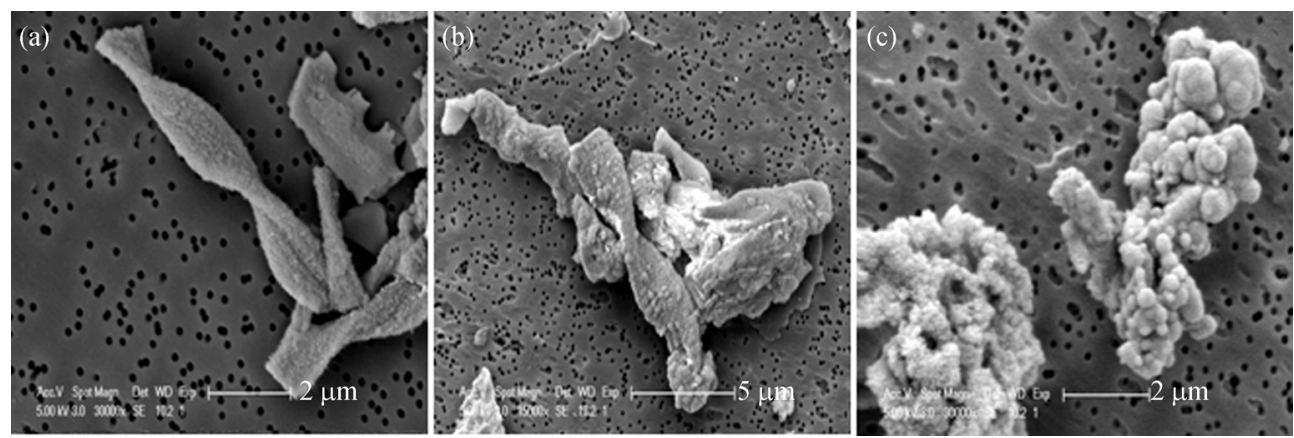

图 5 TS-a 样品 G 型铁氧化菌表面矿物分布

（a) 细菌表面无矿物分布; (b) 细菌表面少量矿物颗粒分布; (c) 细菌表面几乎被矿物完全包裹 
$K_{d}=[M e$ 固相 $] /[M e$ 液相 $]$,

其中 $[M e$ 固相]代表固相沉淀铁泥中金属元素含 量; [Me 液相]代表渗漏水中微量金属元素的浓度.

金属元素在固相铁氧化物中的分配系数 $K_{d}$ 的计 算的结果见表 2 . 从中可以看出, $K_{d}$ 的变化范围为 $10^{1.05} \sim 10^{5.45}$, 表明金属元素在沉淀铁泥中具有明显的 富集, 其中 $\mathrm{Fe}, \mathrm{Co}$ 等具有较高的分配系数, 稀土元素 次之. 并且两处渗漏水微量金属元素的分配系数 $K_{d}$ 值也存在一定的差异, 其值要略小于东北太平洋胡 安德富卡Axial洋中脊火山喷口铁氧化物 ${ }^{[35]}$, 但与瑞 士东海岸的铁氧化物基本相当 ${ }^{[38]}$.

由上述可知, 生物成因铁氧化物 (Biogenic iron oxides, BIOS)主要由 2 个部分组成, 即铁氧化物和铁 细菌有机质. 前人大量的研究认为铁氧化物尤其是 隐晶质的水铁矿, 其分布广泛且表面具有较强的化 学反应活性, 因此是金属元素主要的吸附剂 227,31$]$. 更 为重要的是, 细菌的参与大大提高了BIOS对金属元 素的富集. Ferris等人 ${ }^{[37]}$ 的研究结果表明BIOS中细菌 有机质所占的比例大小直接影响金属的吸附程度. 这是由于细菌数量的多寡直接关系到细胞表面可反 应的两性有机吸附点(如羟基, 磷酸羟基等)供给量的
大小. 当二价铁的浓度高于细胞的表面吸附能力,固 相BIOS组成主要为铁的氧化物, 如水铁矿; 反之, 当 二价铁的数量减少或者细菌数量增大，则细菌有机 质在BIOS中所占的比例升高. 不同区域地下水环境 下固相BIOS中微量金属元素的富集程度差异则可能 是由于细菌有机质和铁氧化物之间的比例不同造成 的 ${ }^{[38,46]}$. Day等人 ${ }^{[47]}$ 亦认为微生物细胞相对于铁氧化 物具有较高密度的表面吸附点, 同时细菌有机质进 入铁氧化物可降低固相BIOS的等电位差, 因此, 在 相对恒定的 $\mathrm{pH}$, 随着细菌有机质在BIOS中含量的 增大，微量金属元素的富集程度也将加剧. 另外，由 于微量金属元素在有机吸附和无机组成之间具有不 同的亲和力, BIOS中沉淀的有机颗粒对一些金属如 $\mathrm{Cu}$ 和 $\mathrm{Zn}$ 具有较强的亲和力. 与此同时, BIOS随着时 间的推移，一些被吸附的金属离子可被重新解析或 释放, 而其他一些金属离子(如 Co) 在晶体生长的过程 中则滞留并进入铁氧化物中 ${ }^{[40,48]}$, 这可能即是 $\mathrm{Co}$ 在 固相BIOS中表现较高的 $K_{d}$ 的重要原因之一. BIOS对 微量金属元素具有强烈的富集作用，表明铁氧化菌 对地下水环境中的微量金属元素迁移和归宿产生重 要的影响.

表 2 渗漏地下水和沉淀铁泥中微量元素含量及分配系数 $\left(K_{d}\right)$

\begin{tabular}{|c|c|c|c|c|c|c|}
\hline 元素 & $\mathrm{TS}-\mathrm{a}$ 水体 & TS-a 铁泥 & $K_{d}(\mathrm{TS}-\mathrm{a})$ & TS-b 水体 & TS-b 铁泥 & $K_{d}(\mathrm{TS}-\mathrm{b})$ \\
\hline $\mathrm{Fe}$ & 13529.6 & $670.1^{\text {a) }}$ & 4.69 & 9581.6 & $587.8^{\mathrm{a})}$ & 4.78 \\
\hline $\mathrm{Mn}$ & 3.98 & 1125.56 & 2.12 & 2.12 & 985.43 & 2.66 \\
\hline Sc & 1.41 & 175.50 & 2.09 & 0.38 & 194.50 & 2.71 \\
\hline $\mathrm{Cr}$ & 107.00 & 1225.00 & 1.05 & 12.8 & 1560.00 & 2.08 \\
\hline Co & 0.03 & 374.00 & 4.09 & 0.76 & 1150.00 & 3.17 \\
\hline $\mathrm{Ni}$ & 7.29 & 990.00 & 2.13 & 6.11 & 1605.00 & 2.41 \\
\hline $\mathrm{Cu}$ & 17.60 & 2165.00 & 2.08 & 10.8 & 1505.00 & 2.14 \\
\hline $\mathrm{Zn}$ & 157.00 & 4070.00 & 1.41 & 66.2 & 6600.00 & 1.99 \\
\hline $\mathrm{Ga}$ & 0.03 & 178.50 & 3.77 & 0.05 & 166.00 & 3.52 \\
\hline $\mathrm{Rb}$ & 0.26 & 725.00 & 3.44 & 0.24 & 770.00 & 3.50 \\
\hline $\mathrm{Sr}$ & 1.05 & 1355.00 & 3.11 & 1.00 & 755.00 & 2.87 \\
\hline $\mathrm{Y}$ & 0.03 & 458.50 & 4.18 & 0.04 & 395.50 & 3.99 \\
\hline $\mathrm{Zr}$ & 1.02 & 222.50 & 2.33 & 5.51 & 257.50 & 1.66 \\
\hline $\mathrm{Nb}$ & 0.13 & 51.00 & 2.59 & 0.11 & 69.00 & 2.79 \\
\hline $\mathrm{Cs}$ & 0.01 & 72.00 & 3.85 & 0.01 & 64.00 & 3.80 \\
\hline $\mathrm{La}$ & 2.70 & 1440.00 & 2.72 & 1.61 & 815.00 & 2.70 \\
\hline $\mathrm{Ce}$ & 1.70 & 2510.00 & 3.16 & 0.62 & 1685.00 & 3.43 \\
\hline $\operatorname{Pr}$ & 0.09 & 277.00 & 3.48 & 0.11 & 177.50 & 3.20 \\
\hline $\mathrm{Sm}$ & 0.02 & 175.00 & 3.94 & 0.04 & 132.00 & 3.51 \\
\hline $\mathrm{Lu}$ & 0.01 & 5.00 & 2.69 & 0.01 & 5.00 & 2.69 \\
\hline $\mathrm{Hf}$ & 0.02 & 5.50 & 2.43 & 0.14 & 7.00 & 1.69 \\
\hline $\mathrm{Pb}$ & 3.99 & 660.00 & 2.22 & 2.89 & 845.00 & 2.46 \\
\hline
\end{tabular}

a) 单位为 $\mathrm{mg} / \mathrm{g}$, 其他单位均为 $\mu \mathrm{g} / \mathrm{kg}$; 分配系数 $K_{d}$ 为取以 10 为底的对数值 


\section{3 结论}

通过对浙江舟山海岸带渗漏地下水现代生物矿 化过程及生物成因铁氧化物化学组成的研究, 可得 出如下几点结论:

(i) 海岸带渗漏地下水的物理化学组成受古木 堆积、海水及地下水的混合等过程的影响, 不同来源 的水体的混合作用引起氧化还原电位、氧含量和二价 铁浓度发生明显的梯度变化, 这为嗜中性铁氧化菌 Leptothrix ochracea 和 Gallionella ferruginea 的生长 提供了理想的生存条件; 同时, 水体的物理化学特征 又严格制约这两种铁氧化菌的丰度分布.

(ii) 铁氧化菌的矿化产物主要为隐晶质的水铁
矿, 并且铁氧化菌矿化过程经历不同阶段, 即从细胞 壁表面矿化、细胞内部部分矿化直至整个细胞完全被 矿化. 该铁渗漏水系统的微生物矿化作用形成的隐 晶质的水铁矿由于受细菌、少量 Si 及温度等多因素 限制, 制约其向良好晶形发展.

(iii) 生物成因铁氧化物包含铁氧化物和细菌有 机质, 由于细胞表面具有较高密度的两性有机吸附 点(如羟基, 磷酸羟基等), 同时细菌有机质进入铁氧 化物可降低固相 BIOS 的等电位差, 加剧金属元素尤 其是 $\mathrm{Fe}$ 和 $\mathrm{Co}$ 在固相 BIOS 中的富集, 故铁细菌及其 矿化产物对该地下水环境中金属元素的生物地球化 学循环产生重要的影响.

\section{参考文献}

1 Ehrlich H L. Geomicrobiology of iron. In: Ehrlich H L, ed. Geomicrobiology. New York: Marcel Dekker Inc, 2002. 345-428

2 Ferris F G, Tazaki K, Fyfe W S. Iron oxides in acid mine drainage environments and their association with bacteria. Chem Geol, 1989, 74: $321-330$ [DOI]

3 Baker B J, Banfield J F. Microbial communities in acid mine drainage. FEMS Microbiol Ecol, 2003, 44: 139-152[DOI]

4 陆建军, 陆现彩, 朱长见, 等. 氧化亚铁杆菌对矿山酸矿水中金属污染元素分布的影响. 南京大学学报(自然科学版), 2005, 41(2): $113-119$

5 蒋磊, 周怀阳, 彭晓形.广东云浮硫铁矿山氧化亚铁硫杆菌的分离及生长规律研究。高校地质学报, 2006, 12(1): 93一 97

6 Emerson D. Microbial oxidation of $\mathrm{Fe}(\mathrm{II})$ at circumneutral pH. In: Lovley D R, ed. Environmental Microbe-Metal Interactions. Washington DC: ASM Press, 2000. 31-52

7 Emerson D, Weiss J V. Bacterial iron oxidation in circumneutral freshwater habitats: Findings from the field and the laboratory. Geomicrobiol J, 2004, 21: 405-414 [DOI]

8 Kasama T, Murakami T. The effect of microorganisms on Fe precipitation rates at neutral pH. Chem Geol, 2001, 180: 117-128[DOI]

9 James R, Ferris F G. Evidence for microbial-mediated iron oxidation at a neutrophilic groundwater spring. Chem Geol, 2004, 212: 301311 [DOI]

10 Emerson D, Weiss J V, Megonigal J P. Iron-oxidizing bacteria are associated with ferric hydroxide precipitates (Feplaque) on the roots of wetland plants. Appl Environ Microbiol, 1999, 65: 2758-2761

11 Sobolev D, Roden E E. Characterization of a neutrophilic, chemolitho autotrophic Fe( II )-oxidizing $\beta$-proteobacterium from freshwater wetland sediments. Geomicrobiol J, 2004, 21: 1-10 $\underline{\text { DOI }]}$

12 Edwards K J, Bach W, McCollom T M, et al. Neutrophilic iron oxidizing bacteria in the ocean: their habitats, diversity, and roles in mineral deposition, rock alteration, and biomass production in the Deep Sea. Geomicrobiol J, 2004, 21: 393-404 [DOD]

13 Fortin D, Ferris F G, Scott S D. Formation of Fe-silicates and Fe-oxides on bacterial surfaces in hydrothermal deposits collected near the Southern Explorer Ridge in the Northeast Pacific Ocean. Am Mineral, 1998, 83: 1399-1408

14 Roden E E, Sobolev D, Glazer B, et al. Potential for microscale bacterial Fe redox cycling at the aerobic-anaerobic interface. Geomicrobiol J, 2004, 21: 379-391[DOI]

15 Weber K A, Achenbach L A, Coates J D. Microorganisms pumping iron : anaerobic microbial iron oxidation and reduction. Nature Rev Microbiol, 2006, 4: 752-764 $\underline{\text { [DOI] }}$

16 Martinez R E, Smith D S, Pedersen K, et al. Surface chemical heterogeneity of bacteriogenic iron oxides from a subterranean environment. Environ Sci Technol, 2003, 37: 5671-5677 [DOD]

17 Chan C S, De Stasio G, Welch S A, et al. Microbial polysaccharides template assembly of nanocrystal fibers. Science, 2004, 303: 
1656-1658[DOI]

李一良，王汝成，周根陶，等。微生物成矿。高校地质学报, 2005, 11(2): 167-180

Newman D K, Banfield J F. Geomicrobiology: Molecularscale interactions underpin biogeochemical systems. Science, 2002, 296: 1071-1077[DOI]

陈骏，姚素平. 地质微生物学及其发展方向. 高校地质学报, 2005, 11(2): 154-166

戴永定, 宋海明, 沈继英. 河北宣龙铁矿化石细菌. 中国科学 D 辑：地球科学, 2003, 33(8): 751-759

Allwood A C, Walter M R, Kamber B S, et al. Stromatolite reef from the Early Archaean era of Australia. Nature, 2006, 441: 714$718[\mathrm{DOI}$

McKay D S, Gibson Jr E K, Thomas-Keprta K L, et al. Search for past life on Mars: Possible relic biogenic activity in Martian meteorite ALH84001. Science, 1996, 273: 924-930[DOI]

Maher B A, Taylor R M. Formation of ultrafine-grained magnetite in soils. Nature, 1998, 336: 368 - 370[DOI]

贾蓉芬, 颜备战, 李㭉森, 等。陕西段家坡黄土剖面中趋磁细菌特征与环境意义。中国科学 D 辑: 地球科学, 1996, 26(5): 411 -416

孙立广, 谢周清, 沈显生, 等.浙江朱家尖观音湾古木层的发现及其意义. 自然杂志, 2000, 22(6): 354一 358

Ferris F G. Biogeochemical properties of bacteriogenic iron oxides. Geomicrobiol J, 2005, 22: 79—85[DOI]

Hallbeck L, Pedersen K. Benefits associated with the stalk of Gallionella ferruginea, evaluated by comparison of a stalkforming and non-stalk-forming strain and biofilm studies in situ. Microb Ecol, 1995, 30: 257-268

Hallberg R, Ferris F G. Biomineralization by Gallionella. Geomicrobiol J, 2004, 21: 325-330

Fortin D. What biogenic minerals tell us? Science, 2004, 303: 1618-1619

Fortin D, Langley S. Formation and occurrence of biogenic iron-rich minerals. Earth-Sci Rev, 2005, 72: 1-19 [DOI]

Søgarrd E G, Aruna R, Abraham-Peskir J, et al. Conditions for biological precipitation of iron by Gallionella ferruginea in a slightly polluted ground water. Appl Geochem , 2001, 16: 1129—1137 [DO]

Hallbeck L, Pedersen K. Autotrophic and mixotrophic growth of Gallionella ferruginea. J Gen Microbiol, 1991, 137: 2657-2661

Kennedy C, Scott S D, Ferris F G. Characterization of bacteriogenic iron oxide deposits from Axial Volcano, Juan de Fuca Ridge, Northeast Pacific Ocean. Geomicobiol J, 2003, 20: 199-214 [DOI]

Ueshima M, Tazaki K. Possible role of microbial polysaccharides in nontronite formation. Clays Clay Miner, 2001, 49: 292 - 299 [DOI]

Emerson D, Moyer C L. Neutrophilic Fe-oxidizing bacteria are abundantat the Loihi Seamount hydrothermal vents and play a major role in Fe oxide deposition. Appl Environ Microbiol, 2002, 68: 3085-3093[DOI]

Ferris F G, Konhauser K O, Lyven B, et al. Accumulation of metals by bacteriogenic iron oxides in a subterranean environment. Geomicrobiol J, 1999, 16: 181-192[DOI]

Warren L A, Ferris F G. Continuum between sorption and precipitation of Fe (III) on microbial surfaces. Environ Sci Technol, 1998, 32: $2331-2337$ [DOI]

Stumm W, Morgan J J. Aquatic Chemistry: Chemical Equilibria and Rates in Natural Waters. 3rd ed. New York: Wiley-Interscience, 1996. 1040

Daughney C J, Fortin D. Mineral adsorption and absorption by biological cells. In: Hubbard A, ed. Encyclopedia of Surface and Colloid Science. New York: Marcel Dekker Inc, 2002. 3430-3446

Daughney C J, Fowle D, Fortin D. The effect of growth phase on proton and metal adsorption by Bacillus subtilus. Geochim Cosmochim Acta, 2001, 65: 1025-1035[DOI]

彭晓堁, 周怀阳, 吴自军, 等. 热泉微生物的矿化作用和机制：来自华南富硅热泉光合自养微生物席中的证据. 科学通报, 2007, 52(1): 89-99

Banfield J F, Welch S A, Zhang H, et al. Aggregation-based crystal growth and microstructure development in natural iron oxyhydroxide biomineralization products. Science, 2000, 289: 751-754 [DOD]

Vempati P K, Loeppert R H. Influence of structural and adsorbed Si on the transformation of synethetic ferrihydrite. Clays Clay Miner, 1989, 37: 272-279 [DOI]

Kennedy C B, Scott S D, Ferris F G. Hydrothermal phase stabilization of 2-line ferrihydrite by bacteria. Chem Geol, 2004, 212: 269$277 \underline{\text { DOI] }}$

6 Fein J B, Daughney C J, Yee N, et al. A chemical equilibrium model for metal adsorption onto bacterial surfaces. Geochim Cosmochim Acta, 1997, 61: 3319-3328 [DOI]

Day G M, Hart B T, Mckelvie I D, et al. Adsorption of natural organic-matter onto goethite. Coll Surf A Physiochem Eng Aspects, 1994, 89: 1-13[DOI]

Ferris F G, Hallberg R O, Lyven B, et al. Retention of strontium, cesium, lead and uranium by bactrrial iron oxides from a subterranean environment. App Geochem, 2000, 15: 1035-1042 [DOD] 